\title{
A Study on the Application of Porcelain Painting in Furniture
}

\author{
Zhang Wei, Yu Shan Zhang \\ Department of Furniture art design, Central South University of Forestry and Technology, HuNan Province, China \\ 447071492@qq.com,532607055@qq.com
}

\begin{abstract}
On the basis of concluding the definition of porcelain painting and its technique, this article analyzes the mode of combination of porcelain and furniture, and the possibility of applying porcelain painting in furniture, so as to extend the cultural connotation of modern inertial design by applying this new decoration material.

Index Terms - Porcelain, Porcelain Painting, Furniture

\section{Introduction}

China has a long history of porcelain culture. Chinese porcelain boasts for its cultural deposits and unique manifestation, and become a brilliant achievement which is famous across continents. [1]The porcelain works nowadays are no longer regarded as articles for everyday use or artistic decorations, but a carrier of the long history of Chinese nation. The porcelain art has been developing with the modern art movement.
\end{abstract}

\section{The Characteristics and Aesthetic Value of Porcelain Art}

\section{A. Characteristics}

The porcelain material consists of oxide, nitride, boride and carbide. With kaolinite as the main mineral resource, this weathering aluminum silicate consists of the following chemical elements: (Al1.8 Fe0.1 Mg0.2) [Si2O5] (OH)4, $\mathrm{Al} 2 \mathrm{O} 3>30 \%$, refractability $>1580^{\circ} \mathrm{C}$. With the characteristics of high intensity, high rigidity, corrosion resistance and fire standing, porcelain material has now become a well recognized new material in many fields. In the 20th century, with the exploration and development of the porcelain industry, porcelain material has now been applied in many new fields, for example, atomic economy industry and electronic industry. New types of porcelain products emerge from traditional craft. According to their function, porcelain products can be divided into daily consumer goods and aesthetic art works, besides, there are also porcelain for architecture and special industry.

\section{B. Aesthetic value}

The invention of ceramics symbolized the beginning of New Stone Age, which boasts its history of 10 thousands years. Owning to different ceramic material in different locations, the tactile sensation and color differ from each other accordingly. The colors of ceramic works include red, black, grey and even multiple colored, which is a great proof of Chinese people's imagination and creativity.

To a ceramic art, there is no definite division standard between function and decoration. These two elements develop with each other and become a dialectical unity. The view of contemporary craft men has been widened; some artists even abandoned the practical function of artificial products, and emphasize the spiritual aesthetic value. A modern porcelain art work on one hand has its practical function, on the other hand, illustrates the characteristics of clay modeling. As a joint production of contemporary art theory and scientific technology, the works now on one hand belong to the scope of modern art, on the other hand, extend the functional meaning of traditional porcelain works.

\section{The Applied Mode and Craft of Porcelain Painting in Furniture}

Porcelain, as a representative form of traditional Chinese object, is also a material of traditional furniture. As a furniture material, it has certain aesthetic attribute and material attribute. As a cultural carrier, it has played a special role in traditional Chinese culture. With the high unity of its function and aesthetic meaning, porcelain has become a symbol of Chinese aesthetic culture.

\section{A. the definition of porcelain painting}

Porcelain painting refers to a planar handicraft painted by special chemical paint on a blank porcelain plane and then baked in high temperature. Porcelain painting can be mounted and assembled into a folding screen for people to appreciate. The history of porcelain painting can be traced back to Qing Dynasty. However, the most genuine porcelain painting came into being in the mid Ming Dynasty. It had reached its height of splendor in the mid Qing Dynasty. Just as the name implies, the porcelain painting is an art form with porcelain as its carrier. According to historical record, there are two kinds of ancient porcelain painting which are well preserved now: one is as a subordinate part of furniture or other living goods; the other is an independent art form since Ming Dynasty.

\section{B. Porcelain Painting as a Decoration on Furniture}

1) specification: The size of a porcelain painting depends on the shape and size of the furniture, as well as the position and sculpts of the decorated part. The outline of the porcelain painting is divided into geometrical form and non-geometrical form. The former includes square, rectangle, rotundity and ellipse, etc; while non-geometrical form includes gourd, bat, folding fan and fish. The size length varied from $3 \mathrm{~cm}$ to 1 meter. However, considering about the storage and aesthetical meaning, people think the proper size length should be 20 to $60 \mathrm{~cm}$.

2) Dermatoglyphic Pattern: There are abundant types of 
dermatoglyphic pattern of porcelain painting. The main themes are: flowers and birds, mystic beasts, dramatis personas, landscapes, geometrical waref, calligraphy, and religion. Among them, the plant elements such as bamboo, gourd, megranate, lotus and plum blossom are used to symbolize good luck and sublimity; while the dragon and phoenix suggest royalty and imperial power; the ancient daily life elements derived from traditional dramas such as The Romance of Western Chamber and Water Margin, which demonstrated the ancient people's daily life and local custom. The geometrical pattern is also called abstract pattern. The geometrical patterns on traditional ceramic works are a vivid demonstration of Chinese ancient culture. Different decorative patterns reflected the daily lives and custom at that time and changed according to different political and culture background. Some patterns appeared in a particular dynasty has become a symbol of that time.

3) Color: To evaluate whether the color of a porcelain work is successful or not, the key point is whether the color can fully express the artist's emotion, so as to arouse an aesthetical sympathy in the spectators' hearts. There are so many different colors of porcelain painting: blue and white, blue and white with copper red colors, five colors, plain tricolor, Doucai contrasting colors, famille rose, grisaille painting, light crimson decoration, etc. The history of blue and white porcelain can be traced back to at least a thousand years ago. Its unique charming blue attracted people from generation to generation. The pigment of blue and white porcelain contains chromatic chemical elements such as iron and manganese. After burned in the kiln, the color of the blue and white porcelain turned into saturated blue color with slight green, or sometimes purple, which brings people the impression of stillness, elegance, crystal and simplicity.

\section{The decoration of the Porcelain Painting on furniture}

Usually, we adopt the embedded method to combine porcelain plate painting and furniture, and make sure that the furniture's surface is smooth with no bumping up. The porcelain painting wooden furniture's technology is similar to lacquer art with slightly difference. The furniture will be designed first on the paper, and draw the picture of the porcelain painting on the graphics. Then mount groove on the graphics, and make sure that the groove and porcelain contours. The bottom and edges should be engraved polished to ensure its bonding with porcelain painting. Embedded the porcelain painting into the groove by using glue, and make sure all parts is adhesive after pressing with a heavy cement guarantee. At last, rub the surface with wax or paint, and then it is finished.

Flush method is more steady and introverted, and this looks simple and subtitle. And the porcelain furniture is very practical in our daily life such as the stool, cabinet and etc.

\section{The Practical Analysis for the Porcelain Painting Furniture}

Compared with other furniture, the porcelain painting furniture can express more various topics with better performance capabilities. Combined with the popular glaze process, the ceramics, the painting and the furniture come to a perfect unity.

\section{A. The Application for the Porcelain Painting on classic furniture}

From the middle-late in the Ming Dynasty, Chinese people were more and more admiring the naturalism of the mahogany which was elegant, simple and reflecting the traditional Chinese "Heaven" thought. The Qing Dynasty and modern furniture added the texture and decorative carving in the $\log$ s so that the surface of the furniture is not only the simple wood grain but also the mix-colors of the different materials. The porcelain painting is widely used in the traditional furniture such as the ocean bed, drawers and curio with its unique characteristics. Figure 1 is showing the early Qing Dynasty porcelain painting Ocean bed in the rosewood inlay. (The length: $248 \mathrm{~cm}$, the width: $131.5 \mathrm{~cm}$, the height: $92 \mathrm{~cm})$ This bed is rosewood porcelain inlay furniture with rosewood framework. The bed enclosed on three sides with nine screens. The screens are the ruffle mosaic colorful floral patterned tiles with deep purple plain rosewood stark. This structure is highlighting the strong and clever unity.

Figure 2 is the sandalwood waist stool with porcelain surface. This stool is embedded with the face-centered inlaid blue and white porcelain pieces, and burning papers is designed for this purpose. Center is a floral tiles regiment tiger treasure fungus, blue and white color, surrounded by a wide white outflow side, giving the delightful feeling.

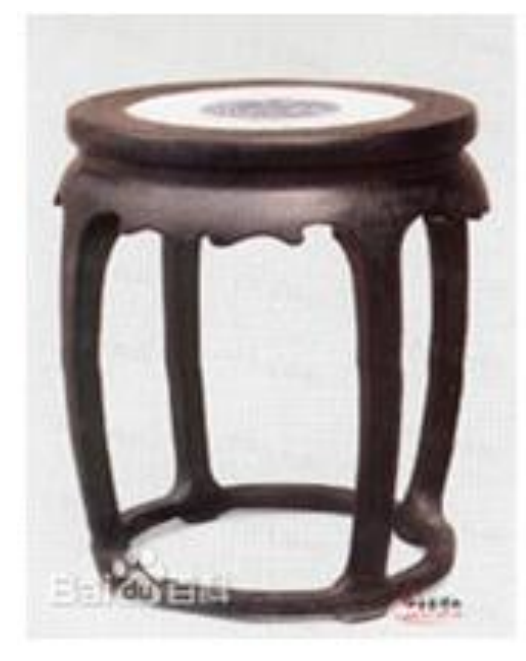

Fig. 1 


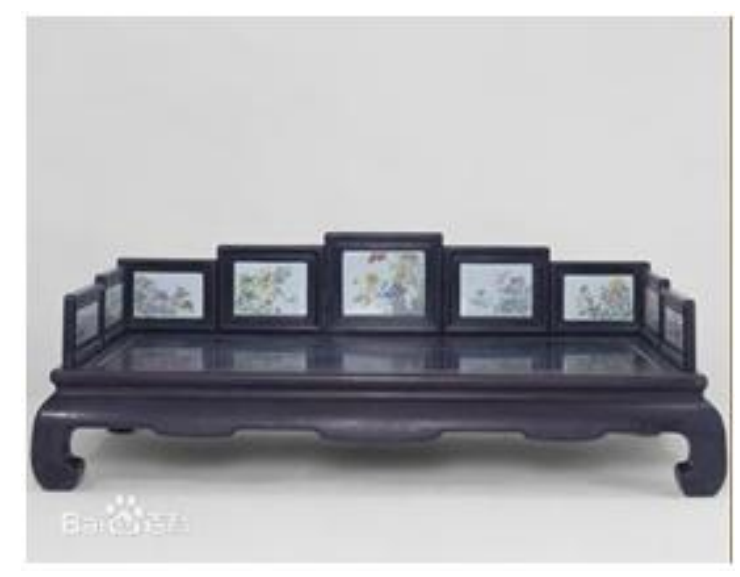

Fig. 2

\section{B. The Porcelain Painting's Application in Modern Furniture}

Recently, some designers start to explore the porcelain's application in modern furniture. Meanwhile, the porcelain painting working as a new kind of decoration materials has a bright future in its modern usage.

Figure 3 shows "Yin Yang Tai Chi porcelain inlay chair" which is designed by Haichen, the furniture is made of pine, chairs face is embedded with hand-painted blue and white porcelain high temperature plate from Jingdezhen. This chair's design idea is out of change, "yin" and "yang" correspond, and its meaning is the performance of the spatial relationship between two people, a man and a woman, like "yin" and "yang" poles, blue and white porcelain painting pattern was also the case on the interaction of "yin" and "yang", with a mutual independent casual sense. Figure 4 shows lotus cabinets which is made from the Pureland, counter using four different patterns of porcelain decoration, each lotus posture is both elegant and very dynamic. Porcelain materials used bright bold pattern, red and green colored strongly increases the visual impact. You can also feel the touch lines on porcelain bump, more three-dimensional.

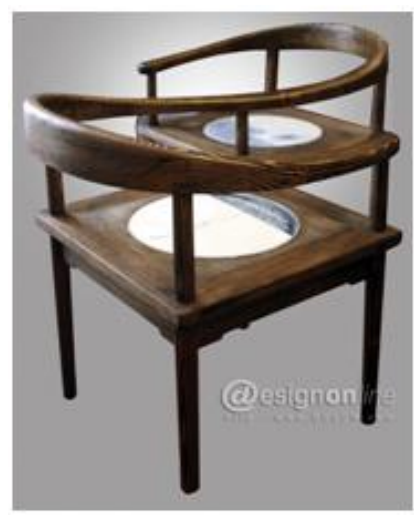

Fig. 3

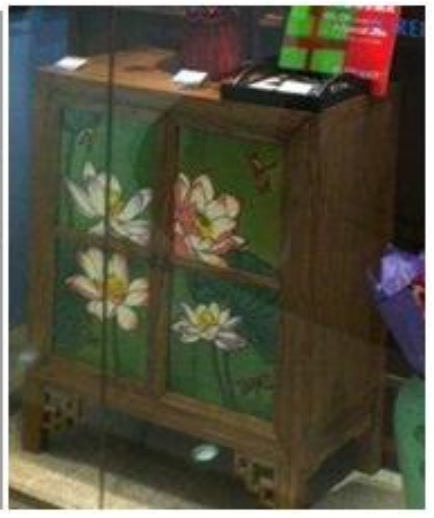

Fig. 4

\section{Conclusion}

Porcelain painting is one of the important decorative craft, decorative craft combined with other Chinese furniture created a unique artistic style. Hope in the future of the furniture design, designers can have more understanding of the process of artistic porcelain painting to handle inherit ance relationship between tradition and artistic innovation, and actively create a distinctive contemporary Chinese porcelain painting furniture.

\section{References}

[1] Changlin Wan, View the Chinese Porcelain Art from the Culture Aspect. China Porcelain Press.vol. 40, no. 1, pp. 67-68, Feb 2004.

[2] Information on http://www.dpm.org.cn/index1280800.html\#

[3] Information on

http://www.dolcn.com/data/cns_1/gallery_41/awards_412/aind_4121/200 6-01/1136822995-2.html 